\title{
Kajian:
}

Pembelajaran PPKn

\section{PERANANAN KEPALA DESA DALAM MENINGKATKAN EFEKTIVITAS PELAYANAN PUBLIK ( STUDI: DIDESA PULO BARGOT )}

\author{
${ }^{1}$ Nisa Pebriani, ${ }^{2}$ Agus Anjar \\ Program Studi Pendidikan Pancasila dan Kewarganegaraan \\ STKIP Labuhanbatu, J1.SM Raja No 126 A, Rantauprapat \\ Email: nisapebrianti@gmail.com
}

\begin{abstract}
Abstrak
Pemerintah Desa adalah penyelenggara urusan pemerintah oleh pemerintahan Desa dan Badan Permusyawaratan Desa yang mengatur dan mengurus kepentingan-kepentingan masyarakat setempat berdasarkan asal-usul dan adat istiadat yang diakui dan dihormati dengan sistem pemerintahan Negara Kesatuan Republik Indonesi. Pemerintah Desa disebut juga dengan nama lain ialah Kepala Desa dan staf-staf Desa sebagai unsur penyelenggaraan pemerintahan Desa.Tujuan penelitian ini untuk mengetahui peran Kepala Desa dalam memberikan pelayanan kepala Desa sudah melaksanakan/ memberikan pelayanan publik kepada masyarakat dengan baik. Hasil penelitian ini menunjukkan bahwasanya pihak Kepala Desa dan Staf-staf Desa tentunya sudah memberikan pelayanan yang sudah baik, akan tetapi masih ada perangkat Desa terutama kaurkaurnya tidak memberikan pelayanan yang begitu baik kepada masyarakat yang sesuai diinginkan oleh kepala Desa. Dan kendala yang dialami kepala Desa yaitu padam listrik (PLN), Sumber daya manusia kurang, dan pihak masyarakat tidak melengkapi syarat atau data-data saat ingin melakukan pengurusan surat di kantor kepala Desa.
\end{abstract}

\section{Kata Kunci: Pelayanan Publik, Kepala Desa}


Kajian:

Pembelajaran PPKn

\section{PENDAHULUAN}

Pemerintah Desa adalah penyelenggara urusan pemerintah oleh pemerintah Desa dan Badan Permusyawaratan Desa dalam mengatur dan mengurus kepentingan masyarakat setempat berdasarkan asal-usul dan adat istiadat setempat yang diakui dan di hormati dalam sistem Pemerintahan Negara Kesatuan Republik Indonesia.Pemerintah Desa atau yang disebut dengan nama lain ialah Kepala Desa dan Perangkat Desa sebagai unsur penyelenggaraan pemerintahan Desa.

Fakta yang terjadi dari kualitas pelayanan publik di Desa Pulo Bargot yang masih tergolong lemah yaitu ketika masyarakat sedang melakukan pengurusan surat seperti surat tanah, proses pembuatan yang dilakukan pihak perangkat Desa sangat lambat, bahkan jangka waktu yang diberikan bisa 1-3 hari baru diselesaikan.

Hal tersebut terlihat dari
masih adanya keluhan dari masyarakat,keluhan atau pengaduan yang di lakukan masyarakat seperti : Prosedur yang terlalu banyak,tidak ada memberikan kepastian jangka waktu penyelesaiannya, pengurusan surat-surat Tanah, pembuatan Kartu Keluarga (KK), Kartu Tanda Penduduk (KTP), Surat Buku Nikah, dan sikap petugas yang kurang responsif dan lain-lain.
Tujuandaripenelitianiniadalah:

1. Untuk mengetahui peran Kepala Desa dalam memberikan pelayanan kepada masyarakat Pulo Bargot.

2. Untuk mengkaji apakah Kepala Desa sudah melaksanakan / memberikan pelayanan publik kepada masyarakat dengan baik.

\section{METODE PENELITIAN}

MenurutDarmadi

(2011:7).

PendekatanDeskriptifialah

mengumpulkan data untukmemberikangambarandanpeneg asansuatukonsepataugejala, jugamenjawabpertanyaanpertanyaanyang berhubungandengansuatusubjekpenel itianpadasaatini.Jadidalampenelitiani niadalahpendekatanDeskriptifbermak suduntukmemahamidanmengenalileb ihdalammengenaiPerananKepalaDes adalammeningkatkanefektivitaspelay ananpublik.

MenurutSugiyono(2016:9). Penelitiankualitatifmerupakanmetode penelitian yang berhubungan padafilsafatpostpositivisme, yangdigunakanuntukmenelitipadakon disiobyek yang alamiah.Obyekalamiahmerupakanob yek yang berkembangdan tidakdimanipulasiolehpeneliti, kehadiranpenelititidakmempengaruhi dinamikapadaobyektersebut. 


\section{Kajian:}

Pembelajaran PPKn

\begin{abstract}
Tempatpenelitianinidilakukan
di

Kantor

KepalaDesaPuloBargotKecamatanM arbauKabupatenLabuhanbatu

Utara,tempattersebutdipilihkarename milikisemuaaspekpendukung agar penelitidapatberjalandenganbaik.Ada puntempatpenelitianinidilaksanakan mulaibulan Mei sampaibulanJuli 2019.
\end{abstract}

\section{HASIL PENELITIAN}

\section{Bagaimana PeranKepala Desa dalam memberikan pelayanan publik kepada masyarakat?}

BahwasanyaperanKepalaDesayai tumelindungidanmelaksanakantugasd antupoksiDesadandisediakankotak saran maupunsolusiuntukmenerima saran

darimasyarakatdandisikapisesuaiden ganbaik,

danapabilatidakadatitiktemumakadis elesaikansecaramusyawarah, danhasilmusyawarahselaluterbukada ntransparankepadamasyarakat. Yang diberikanolehkepalaDesasudahmemb erikanpelayanan yang sangatbaikkepadamasyarakat, bisadikatakankepalaDesasebagaipeli ndungbagimasyarakatdalammemberi kanpelayanan.

Akan tetapisebagaisekretarisDesajugaharus menghimbaukepadaseluruh operator Desaharussiapmembantudanmelayan imasyarakatDesapulobargotkhususny a yang membutuhkankepenuhanpengurusans uratmenyuratdikantorDesakitaini,

walapunterkadangsaatmelayanimasy arakatbanyaksekali yang tidakcocokadajuga yang cocoktergantungbagaimanapenilaian masyarakatitusendiri yang menilainya.

daripembahasandiatasbahwasanyapih akkepalaDesaserta stafstafDesatentunyasudahmemberikanp elayanan yang sudahbaik, akantetapimasihadaperangkatDesater utamakaurkaurnyatidakmemberikanpelayanante rbaik kepadamasyarakat Desa yang sesuaidiinginkanolehkepalaDesa, jadidapatdisimpulkanbahwasanyapih akkepalaDesabelumsepenuhnyamem berikanpelayanan yang baikdanefektifterhadapmasyarakat yang inginmelakukanpengurusansuratsuratdikantorDesaPuloBargot.

2. Apa saja yang menjadi kendala kepala Desa dalam memberikan pelayanan publik kepada masyarakat.

Bahwasannyakendala yang dialamikepalaDesaketikamelayanima syarakatyaitutentunyakendalanyaters ebutpastiada, terutamakendalanyaitudikarenakanpa damlistriksaatsedangmelakukanpeng urusansurat, jadijangkapenyelesainyaitujaditertun 


Kajian:
Pembelajarnn PPKn
da. Dan masyarakat pun
sekarangbanyak
yangkurangmemahamidanmelengkap
i data-datarang di
diinginkansaatmelakukanpengurusan
berkas-berkas yang yang
butuhkanolehmasyarakat.
Dapatdisimpulkanbahwakend
ala dialamikepalaDesayaitupadamlistrik
dialang
(PLN), SumberDayaManusiakurang,
danpihakmasyarakattidakmelengkapi
syaratatau
saatinginmelakukanpengurusansurat
di kantorkepalaDesa.

\section{KESIMPULAN}

1. Berdasarkan hasil peneliti diatas dapatdisimpulkan bahwa Peranan Kepala Desa Dalam Meningkatkan Efektivitas Pelayanan Publik Studi Kasus Di Desa Pulo Bargot Kecamatan Marbau Kabupaten Labuhanbatu Utara, Dapat disimpulkan dari pembahasan diatas bahwasanya pihak kepala Desa dan staf-staf Desa tentunya sudah memberikan pelayanan yang sudah baik, akan tetapi masih ada perangkat Desa terutama kaur-kaurnya tidak memberikan pelayanan yang baik kepada masyarakat yang sesuai diinginkan oleh kepala Desa, jadi dapat disimpulkan bahwasanya pihak kepala Desa tidakmaksimaldalam

memberikan pelayanan yang baik dan efektif terhadap masyarakat yang ingin melakukan pengurusan suratsurat dikantor Desa Pulo Bargot.

2. Bahwa kendala yang dihadapi oleh kepala Desa tentang Peranan Kepala Desa Dalam Meningkatkan Efektivitas Pelayanan Publik Studi Kasus Di Desa Pulo Bargot Kecamatan Marbau Kabupaten Labuhanbatu Utara, Dapat disimpulkan bahwa kendala yang dialami kepala Desa yaitupadamlistrik (PLN),

SumberDayaManusianyakurang, dan pihak masyarakat tidak melengkapi syarat dan data-data serta administrasinya saat ingin melakukan pengurusan surat di kantor kepala Desa.

\section{DAFTAR PUSTAKA}

\section{BUKU}

Agustino, Leo, 2016. DasardasarKebijakanPulik, Bandung, Alfabeta.

Azwar, Saifuddin, 2013. MetodePenelitian, Yogyakarta, PustakaPelajar .

Darmadi, Hamid, 2011. MetodePenelitianPendidikan, Bandung, Alabeta. 


\section{Kajian:}

Pembelajaran PPKn

Mukarom, Zaenal, \&Laksana,

Muhibudin, Wijaya, 2015.

ManajemenPelayananPublik,

Bandung, CvPustakaSetia.

Riduan, 2010.Belajar mudah penelitian untuk guru karyawan dan peneliti pemula. Bandung, Alfabeta.

Sugiono, 2016.Metode penelitian kuantitatif dan kualitatifdan $R \& D$, Bandung, CvAlfabeta.

Sugiyono, 2016.MemahamiPenelitiKualitatif, Bandung, Alfabeta.

Sugiono, 2012.MetodePenelitianPendidikanPe ndekatanKuantitatif, Kualitatif, dan $R \& D$. Bandung, Alfabeta.

Widjaja, Haw, 2014.

OtonomiDesaMerupakanOto nomi Yang AsliBulatdanUtuh, Jakarta, PT Raja

GrafindoPersada.

\section{JURNAL}

E Jurnal "Acta Diuma" Volume IV No.2 Tahun 2015. Peranan Kepala Desa

Dalam Pelayanan Publik Jamin Potabuga).

Jurnal, Kristiana, Purba \& Dkk, Peranan Kepala Desa Dalam Meningkatkan

Efektivitas Pelayanan Publik.
Jurnal, Sri Ulina, Volume 7, No.2. Oktober 2014. Tugas dan Fungsi Kapala Desa

Beserta Perangkat Desa Dalam Meningkatkan Kinerja Pada Kantor Desa

Namo Bintang Kecamatan Pancur Batu Kabupaten Deli Serdang.

E Jurnal Suwanti, Administrasi Negara Volume 4 No.1 Tahun 2016. Peranan Kepala Desa Dalam Meningkatkan pembangunan Masyarakat di Desa Ngayu Kecamatan Muara Bengkal Kabupaten Kutai Timur

Jurnal, Yosua T, Panggulu, Volume II No.4 Tahun 2013.EfektivitasKebijakan RetribusiPadaDinasPengelol aanPasarKebersihan Dan Pertamanan Di KabupatenKepulauanTaulau $d$.

\section{UNDANG-UNDANG}

Undang-UndangRepublik Indonesia No.25 Tahun 2009.TentangPelayanan Publik. 